\title{
ANALISIS KOSMOLOGI POLA TIGA DALAM TRADISI NYEUPAH PADA MASYARAKAT SUNDA
}

\author{
Ahda Yunia Sekar \\ Fakultas Industri Kreatif Universitas Telkom \\ Ahdayuniasekar@telkomuniversity.ac.id
}

Received 14 January 2021; accepted 28 June 2021; published 30 July 2021

\begin{abstract}
Nyeupah is a term in Sundanese society which means chewing betel leaves. Nyeupah itself has other terms such as nyirih for the Java area and Nginang for the Sumatra area. Consuming betel leaf has been done by our ancestors since the middle of 15th century, where the Chinese, Indians, Persians and Europeans had made transactions for herbs and spices in Nusantara. The Nyeupah tradition in Sundanese society has long existed and it is proved by the existence of Jangjawokan regarding Nyeupah. Jangjawokan is a Sundanese poem which can be interpreted as containing archaic or ajimantra. This article has been written to analyze the Nyeupah tradition in Sundanese society with a three-pattern cosmological approach to be able to give deeper meaning dealing with this tradition.
\end{abstract}

\section{KEYWORDS}

Nyeupah, Sundanese, Triple Pattern

Cosmology

This is an open access article under the CC-BY-SA license

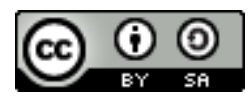

\section{Pengantar}

Nyeupah atau nyirih atau nginang adalah tradisi mengunyah daun sirih yang terdapat pada beberapa tradisi di Nusantara. Nyeupah merupakan istilah dalam masyarakat sunda, sedangkan nyirih dan nginang adalah istilah yang lebih dikenal meluas dalam masyarakat Jawa hingga ke luar Jawa. Mengkonsumsi daun sirih ini sudah dilakukan oleh nenek moyang sejak pertengahan abad ke -15 , dimana bangsa Cina, India, Persia dan Eropa sudah melakukan transaksi rempah-rempah di Nusantara. Menurut penulis sejarah Nusantara, Anthony Reid (1992), tercatat bahwa tradisi mengunyah sirih telah dilakukan sejak lama. Dalam catatan musafir Cina menyebutkan buah pinang dengan pin-lang yang telah dikonsumsi sebagai bagian dari bersirih pinang atau betel-chewing pada dua abad sebelum masehi. Kebiasan mengunyah pinang ini dinilai memiliki arti sangat penting dalam upacara ritus dan kehidupan sosial. (Reid, 1992: 50)

Lebih lanjut dalam bukunya Reid menjelaskan bahwa kegiatan menyirih di Nusantara terdapat dalam catatan seorang pelaut, Antonio Pigafetta, bahwa penduduk setempat sering mengunyah buah yang menyerupai buah Pir yang mereka sebut dengan areca (pinang) yang dibungkus dengan daun sirih. Menurut mereka kegiatan tersebut dapat menyejukan hati, dan apabila mereka berhenti mengkonsumsi itu mereka akan mati.

Melalui penelusuran sejarah tersebut dapat diketahui bahwa nyirih merupakan tradisi yang menyebar di Nusantara. Kedudukan sirih sama dengan teh, kopi, rokok dan minuman keras. Maka tak jarang pada masa itu setiap orang selalu menyuguhkan sirih pada acara-acara sosial. Sirih merupakan simbol dari sopan santun oleh karena itu mereka beranggapan arwah leluhur juga harus diberi sesaji sirih-pinang pada saat upacar ritus yang penting. Dalam masyarakat Jawa tradisi Nyirih terdapat pada saat perayaan sekaten. Nyirih dilakukan oleh para Abdi Dalem keraton dan dijual di arena sekaten berlangsung agar dapat dikonsumsi juga oleh masyarakat umum. Nyirih dalam sekaten menyimbolkan ajaran tauhid dalam hidup. Orang yang nyirih diharapkan dapat mengerti dan selalu teringat oleh Yang Maha Kuasa. Oleh karena itu dalam tradisi sekaten, bahan nyirih ditambahkan bunga Kanthil, yang menjadi simbol agar selalu kanthil (dekat) dengan Yang Maha Kuasa. 


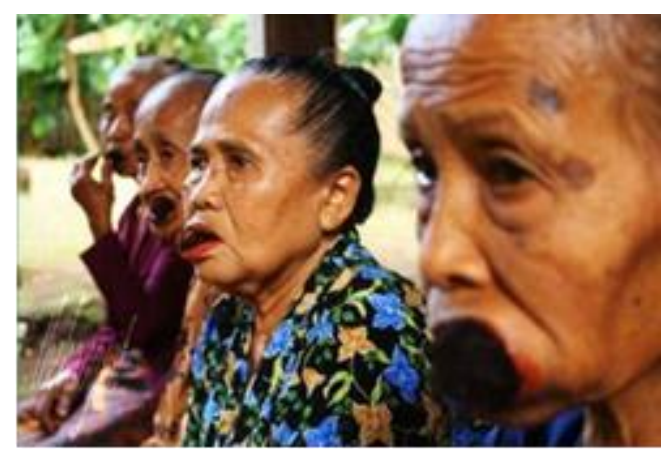

Gambar 1. Kegiatan mengunyah daun sirih

(Sumber: http://reeksternal.blogspot.co.id /2011/03/manfaat-nginang.html. 2017)

Dalam masyarakat Sumatra, sirih dan pinang merupakan simbol penerimaan atau penghormatan tuan rumah terhadap tamu yang berkunjung ke kediamannya. Diceritakan bahwa pada saat Augustin da Beaulieu mengunjungi kesultanan Aceh pada sekitar tahun 1620-1621, ia diterima dengan baik oleh Sultan Iskandar Muda dengan suguhan sirih di dalam sebuah bejana emas besar.

Tradisi nyirih juga terdapat di Kalimantan dengan ditemukannya artefak tempat menyimpan sirih yang disebut penginangan. Tempat penginangan ini termasuk tempat untuk menyimpan bahan-bahan nginang, alat penumbuk kinang, alat pemotong pinang dan tempat untuk meludah. Terdapat banyak jenis artefak penginangan yang ditemukan, tidak hanya terbuat dari logam saja melainkan juga terbuat dari kayu dan anyaman rotan. Tidak hanya itu, ditemukan juga tempat penginangan yang dihiasi dengan manik-manik dan dilapisi dengan emas. (Amurwani Dl dalam Hidayat, 2016)

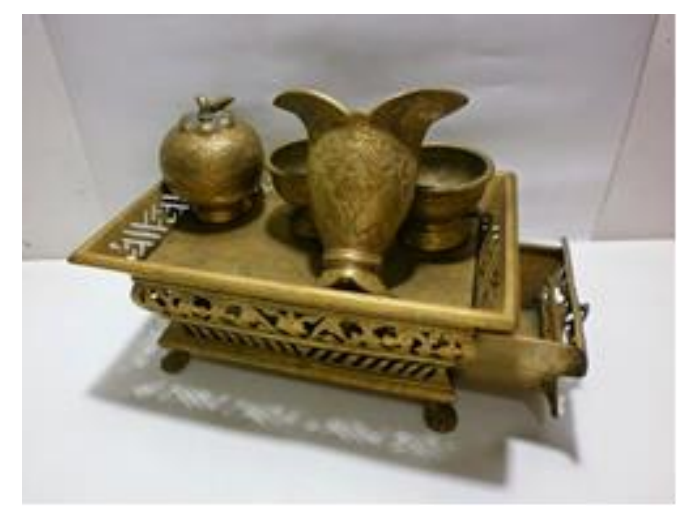

Gambar 2. Tempat penginangan yang terbuat dari kuningan

(Sumber: http://antikpisan.blogspot.co.id/2014_10_01_archive.html. 2017)

Pada setiap daerah, kinang memiliki campuran bahan khas tersendiri. Bahan utama dalam kinang adalah daun sirih, biji pinang dan kapur. Ada yang ditambahkan dengan tembakau, yang berfungsi untuk menggosok gigi. Selain itu ada juga yang menambahkan cengkeh, daun saga, kapulaga dan beberapa bahan yang khas sesuai selera daerah masing-masing.

\section{Pembahasan}

\subsection{Tradisi Nyeupah dalam Masyarakat Sunda}

Keberadaan tanaman sirih di tanah Sunda diprediksi sudah ada pada tahun 1400 atau 1500. Tradisi mengenai sirih dapat ditemukan dalam naskah Bujangga Manik. Tercantun pada naskah Bujangga Manik bahwa Putri Ajung Larang yang terpikat oleh Ameng Layaran alias Bujangga Manik, 
mempersembahkan beragam perlengkapan mengunyah sirih yang sangat istimewa. Seperangkat sirih yang dipersembahkan tersebut merupakan simbol dari ketertarikan sang Putri yang ingin mengikat Bujangga Manik. Diungkapkan oleh ibu Bujangga Manik bahwa sugi tembakau itu disiapkan dengan membentuk, melipat dan menggulungnya diatas paha dan dada oleh sang Putri, dan membelitnya dengan benang dari roknya, supaya dapat "mengikat jejaka, dan menggugah gairahnya" (Setiawan, tanpa tahun).

Nyeupah dalam bahasa Sunda memiliki arti mengunyah sirih. Dalam Sunda kuno memang sulit untuk menemukan informasi literatur mengenai tradisi nyeupah. Tetapi nyeupah sudah menjadi tradisi masyarakat Sunda sejak dulu dibuktikan dengan adanya jangjawokan yang isinya mengisyaratkan nyeupah.

Jangjawokan tersebut begini bunyinya:

Bismillahi suruh panggawe ati

Jambe panglebur ati

Apu panggurit ati

Angker atina Si Anu

Bismillahillahi putih saking bapa nira

Abang saking biang nira

Dadu arana ashadu adep idep.

(Kuswandi, blogkabehbaraya.blogspot.co.id, 2013).

Selain itu ada juga jangjowokan versi yang lain, seperti ini bunyinya:

Seureuh seuri,

Pinang nangtang,

Apuna galuget angen,

Gambirna pamuket angin,

Bakona gulaga sari,

Coh nyah, parapat nyay, leko lenyay,

Cucunduking aing taruk haréndong,

Cucunduking aing taruk paku hurang,

Keuna ku asihan awaking,

Asihan si leugeut teureup.

(Engka Widjaja, 1924:8 dalam Hidayat, 2016)

Jangjawokan adalah puisi Sunda yang dapat diartikan mengandung arkais atau ajimantra. Kata suruh dan seureuh yang terdapat pada dua puisi tersebut merupakan penyebutan daun sirih dalam Bahasa Sunda. Tetapi menurut Ajip Rosidi dalam bukunya Jangjawokan, menganggap jangjawokan merupakan bentuk permintaan atau perintah agar permintaan si pengguna dapat dilaksanakan oleh sang gaib (Taufik, mirwansmart.blogspot.co.id, 2009)

\subsection{Makna Tradisi Nyeupah dalam Masyrakat Sunda}

Dalam tradisi Sunda, seupah atau bahan untuk nyeupah dijadikan simbolis untuk mempertemukan jodoh. Mengacu pada naskah Bujangga Manik, dalam ritual untuk mempertemukan jodoh, biasanya orang tua dari calon lelaki akan mendatangi calon menantunya dengan membawa seupaheun. Dalam artian lain, kegiatan ini diistilahkan dengan ngalamar- melamar, meminta anak perempuan untuk dijadikan calon istri atau menantu. Seupaheun tersebut digunakan untuk nyeupah, atau dalam istilah sawanda berarti ngelamar. (Sauni, 1986)

Praktik melamar menggunakan seupah dalam Sunda tersebut dinamakan dengan lepit. Jika lepit tersebut diterima oleh penerima-pihak keluarga perempuan, maka orang tua dari perempuan akan 
nyeupah dengan seupah tersebut. Apabila lepit tersebut dibuka berarti ada permintaan atau kemauan lain. Namun jika lepit itu dikembalikan kembali berarti lamarannya ditolak.

Perlambangan mengenai jodoh dalam nyeupah juga terdapat istilah lain yaitu nyereuhan. Nyereuhan dapat diartikan merapihkan sirih. Kata kerja lainnya yaitu ngarereuhken dalam bahasa Indonesia berarti meredakan, yaitu mempertemukan jodoh antara perempuan dengan laki-laki (Sauni, 1986). Pada masyarakat Sunda, apabila seorang perempuan sudah terlanjur cinta dengan seorang laki-laki, maka tidak baik jika dibiarkan sehingga akan lebih baik jika dinikahkan. Oleh karena itu ada istilah pepatah dalam bahasa sunda yang berbunyi,

\section{Samara seupaheun teh dibungkus ku seureuh,}

yang artinya, bumbu dalam nyeupah itu harus dibungkus dengan daun sirih. Semua bumbu untuk nyeupah itu harus dibungkus dengan daun sirih sehingga akan nikmat rasanya. Dari istilah pepatah tersebut dimengerti bahwa daun sirih memiliki makna reureuh atau reda. Sehingga keterkaitannya adalah bahwa semua hasrat keinginan laki-laki dan perempuan harus dipertemukan supaya rereuh atau reda, supaya tetap selamat dalam mejalani hidup dan berdampak baik bagi semua pihak (Sauni, 1986).

Dalam budaya lainpun nyeupah atau nyirih merupakan simbol perkawinan atau ajakan untuk bercinta. Sehingga mencampur sirih dengan kapur dan pinang atau bahan lainnya merupakan pelayanan intim yang diberikan perempuan terhadap laki-laki. Perpaduan daun sirih dan pinang merupakan simbol persetubuhan, yaitu bercampurnya rasa dingin daun sirih dengan panasnya buah pinang.

\subsection{Penggunaan nyeupah dalam masyaraka Sunda}

Tradisi nyeupah dalam sunda ini dilakukan oleh siapa saja baik kaum perempuan ataupun lakilaki. Dalam penggunaannyapun tidak ada perbedaan baik dari segi bahan ataupun cara mengkonsumsinya. Pada masyarakat Sunda tidak ditemukan waktu khusus untuk menyepah seperti pada tradisi nginang sekaten. Biasanya mereka menyeupah saat setelah makan, yang difungsikan untuk menyegarkan mulut dan membersihkan gigi.

Dalam sebuah penelitian mengatakan bahwa tradisi nyeupah ini hampir hilang dan bahkan sudah tidak lagi dilakukan oleh masyarakat adat sendiri di kampung Naga. Mereka mengaku bahwa hal tersebut disebabkan bahan-bahan untuk nyeupah sudah tidak mudah lagi ditemukan. Namun, di beberapa kampung masih ada beberapa orang yang masih nyeupah, salah satunya di desa Jelekong (Hidayat, 2016).

\subsection{Komposisi Seupah}

Seupah memiliki beberapa variasi seperti adanya penambahan bahan tambahan. Namun terdapat bahan utama yang harus ada dalam seupah yaitu;

\subsubsection{Daun Sirih}

Dari berbagai macam daun sirih yang tersebar dan tumbuh di Indonesia, daun sirih hijau adalah jenis daun sirih yang sering digunakan untuk nyeupah. Daun sirih hijau ini diyakini memiliki rasa lebih enak dan pas untuk dijadikan seupah.

\subsubsection{Buah Pinang}

Pada masyarakat Sunda, pohon pinang disebut dengan jambe. Buah pinang ini digunakan sebagai campuran apu atau kapur sirih dalam nyeupah. Biasanya buah pinang dipotong kecil-kecil dan dioleskan kapur sirih, sehingga apabila dikunyah akan membuat ludah berwarna merah.

\subsubsection{Gambir}

Gambir merupakan sejenis getah yang dihasilkan dari ekstrak daun dan ranting tumbuhan bernama latin Uncaria gambir. Gambir berwarna coklat kekuningan. dalam nyeupah gambir hanya digunakan dengan porsi sedikit, biasanya dipotong kecil-kecil atau dibubukan. 


\subsubsection{Apu atau Kapur Sirih}

Apu atau kapur sirih terbuat dari endapan batu kapur atau gamping yang direndam dalam air selama satu minggu. Selain itu, kapur sirih juga dapat dibuat dari cangkang kerang yang dihancurkan yang kemudian dibuat pasta. Kapur sirih digunakan hanya sebagai campuran sedikit saja karena dipercaya tidak baik untuk kesehatan apabila terlalu banyak.

Selain keempat bahan utama dalam seupah di atas, terdapat juga bahan-bahan tambahan yang menjadi campuran untuk meningkatkan cita rasa. Bahan-bahan tambahan tersebut diantaranya seperti tembakau yang digunakan untuk nyisig yaitu menggosok gigi, cengkih untuk menambah cita rasa hangat/pedas pada seupah, kulit pohon Lemo yang berkhasiat untuk mengobati sakit gigi, kapulaga yang berkhasiat untuk menyembuhkann sariawan dan yang terakhir ada daun Saga untuk menambah cita rasa manis.

\section{5. . Kosmologi pola tiga pada Nyeupah}

Tradisi nyeupah memang sudah sangat lama dilakukan oleh nenek moyang orang Sunda. Selain banyak manfaat yang diambil untuk kesehatan tubuh, nyeupah ternyata bukan semata perihal konsumsi saja. Menurut cara pandang Sunda, nyeupah mengandung kosmologi pola tiga di dalamnya, atau yang disebut dengan istilah Tritangtu.

Masyarakat Sunda memandang pola tiga penting dalam kehidupan ini, yaitu langit pemberi hujan, tanah (bumi) yang menumbuhkan tanaman, dan manusia yang memungkinkan mengawinkan dari kedua hal tersebut yaitu langit dan bumi. Ini lah yang menyebabkan dikenalnya tiga buana atau dunia, yaitu Buana Nyuncang (atas), Buana Pancatengah (tengah, manusia), dan Buana Larang (bumi). Ketiga macam dunia tersebut memiliki simbol masing-masing yaitu, air untuk dunia atas, batu untuk dunia tengah dan tanah untuk dunia bawah (Sumardjo, 2014).

Pola tiga yang menjadi landasan berfikir masyarakat Sunda tercermin pada artefak budaya dan tradisinya, disimbolkan dalam kesatuan tekad, ucap dan lampah. Dalam artefak budaya dan tradisi Sunda, pola tiga berawal dari adanya dua sama rupa (dua sakarupa) yang saling bertentangan (dualitas). Dari dua sama rupa itu 'terkawinkan' dengan membentuk siger tengah, yaitu suatu ketentuan yang di luar dua sama rupa. Dengan demikian terdapat tiga rupa yang setara (tilu sapamilu) yang sebenarnya adalah kesatuan dari tiga komponen tersebut (hiji eta-eta keneh).

Diagram 1. Tritangtu

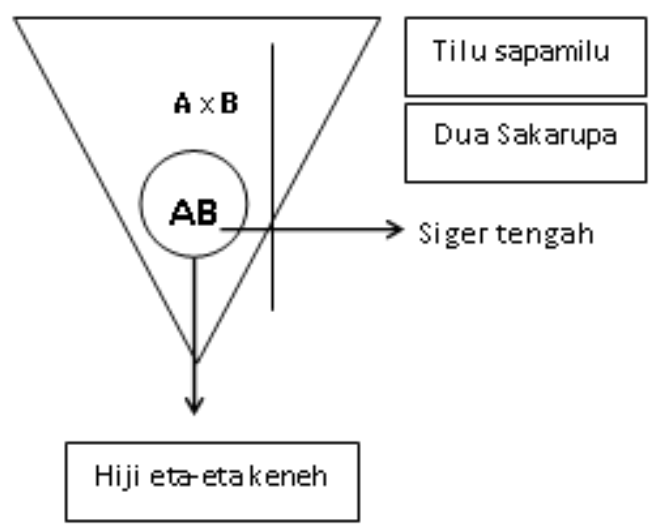

Tak terkecuali dalam tradisi nyeupah. Dari komposisi pembetuk bahan-bahan nyeupah dapat diketahui pola tiga di dalamnya. Buah pinang yang diperoleh dari pohon pinang tumbuh tinggi menjulang ke atas merupakan simbol dari dunia atas. Kapur sirih yang terbuat dari endapan gamping merupakan simbol dari dunia bawah. Sehingga terdapat dualitas di dalam seupah tersebut. Sedangkan daun sirih yang pohonnya tumbuh merambat merupakan simbol dunia tengah. Daun sirih berperan sebagai siger tengah yang dapat menyatukan dualitas tersebut. 
Buah pinang dan gambir yang berwarna kuning kecoklatan merupakan simbol daging. Kapur sirih yang berwarna putih merupakan simbol tulang. Sedangkan daun sirih merupakan simbol kulit yang membungkus daging dan tulang. Oleh karena itu seupah itu sendiri dapat diartikan sebagai simbol manusia. Sehingga mengkonsumsinya dapat diartikan sebagai pelajaran mengenai kehidupan itu sendiri.

Diagram 2. Pemetaan pola tiga pada seupah

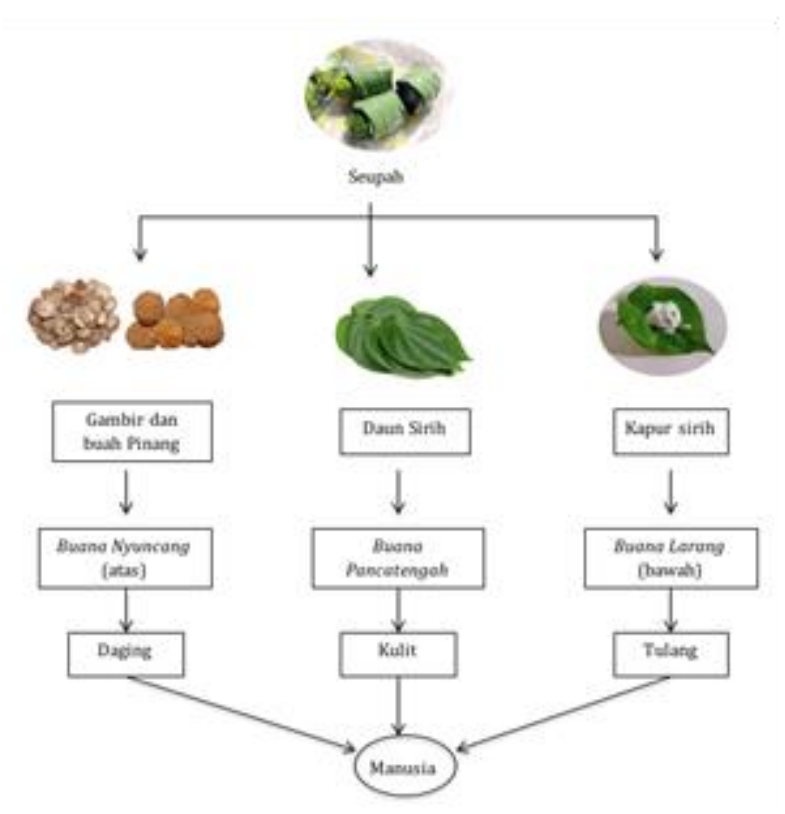

Diagram 3. Pola Tritangtu dalam seupah

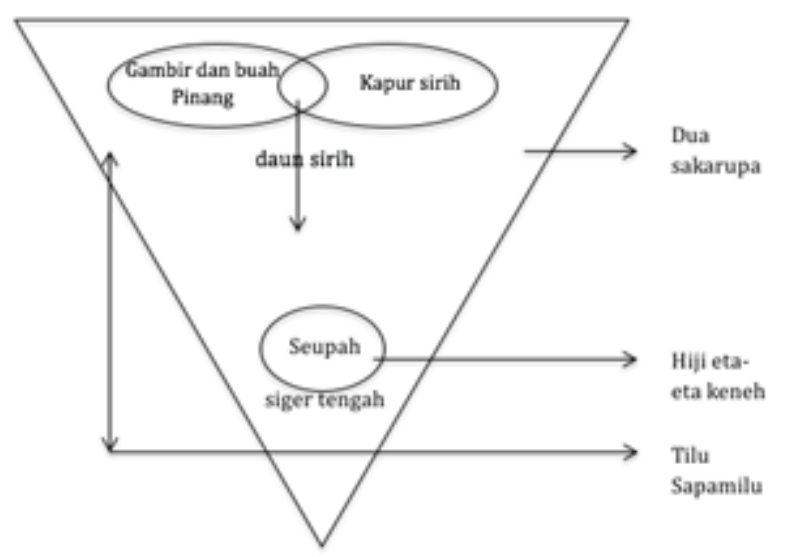

Selain pembacaan pola tiga dalam komposisi bahan seupah, konsep tritangtu juga terdapat pada bagaimana seupah itu dikonsumsi. Seupah yang merupakan penyatuan dari berbagai macam bahan yang dibungkus dengan daun sirih menjadi satu merupakan perwujudan tekad. Sedangkan cara mengkonsumsinya dengan mengunyah kinang berkali-kali merupakan perwujudan dari lampah. Bertemunya tekad dan langkah itu membentuk ucap yang disimbolkan dari bersatunya cairan ludah dan seupah yang menimbulkan warna merah, yang merupakan simbol manusia. 


\section{Kesimpulan}

Seupah atau nyeupah merupakan tradisi masyarakat Sunda yang di dalamnya terdapat cara pandang orang Sunda mengenai kosmologi kehidupan. Seupah berserta komposisi di dalamnya merupakan bentuk tritangtu itu sendiri. Begitu juga bagaimana seupah itu dikonsumsi merupakan wujud tekad, ucap dan lampah orang Sunda. Oleh karena itu, nyeupah merupakan bentuk idelisme nilai-nilai adiluhung yang dijunjung dalam masyarakar Sunda yang di dalamnya memiliki keharmonisan yang akan membawa kebaikan dalam hidup. Hal ini lah yang menyebabkan seupah atau nyeupah menjadi simbol dari seperangkat prosesi perjodohan (lamaran) dalam tradisi Sunda. Seupah menjadi simbol harapan yang akan membawa kebaikan melalui pertemuan dua individu lakilaki dan perempuan dalam ikatan yang sakral yang disebut perkawinan.

\section{Kepustakaan}

Hidayat, Rahman. 2016. Perancangan Informasi Budaya Nyeupah Seureuh di Masyarakat Sunda Melalui Media Buku Ilustrasi. Tesis Unikom :5-20.

Kuswandi, Atin, 2013. Kumpulan Mantra, Ajian, Rajah, Singlar, Jangjawokan, Asihan Sunda. http://blogkabehbaraya.blogspot.co.id/2013/10/ postingan-kali-ini-saya-bahas-tentang.html. Diakses pada 11/03/2017).

Re_eksternal. 2011. Manfaat Nginang. http://reeksternal.blogspot.co.id /2011/03/manfaat- nginang.html. Diakses pada 5/03/2017).

Reid, Anthony. 1992. Asia Tenggara Dalam Kurun Niaga 1450-1680. Jilid 1: Tanah di Bawah Angin. Jakarta: Yayasan Obor Indonesia.

Sauni, S. 1986. Gunana Seureuh. Bandung: Penerbit Tarate.

Setiawan, Hawe. Bujangga Manik dan Studi Sunda. http://file.upi.edu/Direktori /FPBS/JUR._PEND._BAHASA_DAERAH/HAWE_SETIAWAN/makalah/Bujangga_Manik. pdf. Diakses pada 10/03/2017).

Solihin, Lukman. 2015. Menginang atau Menyirih. http://melayuonline.com /ind/encyclopedia/detail/217/menginang-atau-menyirih. Diakses pada 10/03/2017).

Sumardjo, Jakob. 2009. Kosmologi dan Pola Tiga Sunda. Imaji Vol.4, No.2.

Sumardjo, Jakob. 2014. Estetika Paradoks. Bandung: Kelir.

Taufik, A Mirwan. 2009. Jangjawokan Sunda. http://mirwansmart.blogspot.co.id /2009/11/jangjawokansunda.html. Diakses pada 10/03/2017).

Wardiyyah, 2011. Nyeupah Jeung Bulan Kesehatan Gigi Nasional. http://sitijahrotulwardiyyah.blogspot.co.id/2011/10/nyeupah-jeung-bulan-kesehatan-gigi.html. Diakses pada 11/03/2017). 